\title{
Uma abordagem fenomenológica da fome ${ }^{1}$
}

\author{
A phenomenological approach to hunger
}

Maria do Carmo Soares de FREITAS²

\section{RE S U M O}

O presente estudo reúne alguns elementos para aprofundar a compreensão sobre os objetos da saúde e nutrição. Sua dimensão epistemológica refere-se à conjunção da hermenêutica descrita por Paul Ricoeur com a fenomenologia, e proporciona um caminho para a interpretação da fome, a qual é sentida e expressada por diferentes sujeitos em seus contextos sociais específicos. Trata-se de um estudo etnográfico da fome realizado em um bairro popular da cidade de Salvador, Bahia, cujo objetivo é a compreensão do fenômeno da fome, a partir do ponto de vista de atores sociais que vivem em condições de extrema pobreza.

Termos de indexação: fome, fenomenologia da fome, valores sociais.

\section{A B S T R A C T}

This study collects some elements to deepen the understanding of health and nutrition. Its epistemological dimension refers to the hermeneutics of Paul Ricoeur and the phenomenology, and seeks to interpret the phenomenon of hunger, which is felt and expressed by different individuals in their specific social contexts. The approach is based on an ethnographical study of hunger carried out in a poor district in Salvador, state of Bahia; objectively, this work emphasizes an approach to the understanding of the phenomenon of hunger, from the point of view of social actors who live under conditions of extreme poverty.

Index terms: hunger, phenomenology of hunger, social values.

\footnotetext{
${ }^{1}$ Trabalho elaborado a partir da tese de doutorado em Saúde Pública de M.C.S. FREITAS, "Significados da fome: um estudo etnográfico em um bairro popular de Salvador". ISC, Universidade Federal da Bahia, Salvador, 2000.

2 Departamento das Ciências da Nutrição, Escola de Nutrição, Universidade Federal da Bahia. R. Araújo Pinho, 32, Canela, 40110-170, Salvador, Bahia, Brasil.
} 
SOBRE A

FENOMENOLOG I A

Do ponto de vista sócio-antropológico, a compreensão sobre a fome na vida cotidiana tem lugar na revelação dos diversos saberes e práticas relacionados ao corpo e à comida, em condições sociais de precariedade extrema. Estas ações descortinam os valores simbólicos inscritos na dieta famélica do dia-dia, desde o acesso à comida, seu preparo e sua distribuição na unidade familiar, até as diversas associações a comporem o binômio corpo-faminto e alimento, seguindo uma certa lógica interna, específica de um dado grupo social e integrada às relações sociais. Os sentidos e os significados da fome são produtos expressos da dimensão histórica, mas também são representados por valores simbólicos tomados em sua globalidade.

A fome conforme estudo etnográfico realizado em um bairro popular de Salvador, durante oito meses de trabalho no bairro observei e descrevi o cotidiano dos moradores, e, em particular, transcrevi com detalhes suas falas em seus contextos específicos. Conforme o método etnográfico, elegi algumas unidades familiares (em um total de dez) para uma descrição minuciosa da condição de fome. Ela é um fenômeno impregnado no ser humano que viveu ou ainda vive precárias condições de vida, pois a temporalidade, no corpo e na memória, transcende ao evento econômico e social de sua ocorrência. A abordagem fenomenológica vem contribuir para mostrar esta dimensão da fome ainda não descrita na literatura sobre o tema.

A fenomenologia inicialmente descrita por Edmund Husserl, na década de 20, trouxe uma nova discussão no seio das Ciências Humanas, configurando-se como um viés necessário à compreensão da práxis social. Fenômeno, da expressão grega Fainomenon, é derivado do verbo Fainestai, ou mostrar-se a si mesmo, ou aquilo que se mostra ou se manifesta. Faino provém de Fa ou raiz, ou Fos, a qual significa luz. Em outros termos, a fenomenologia trata do que se torna visível em si mesmo e de várias formas (Martins \& Bicudo, 1997). Segundo este autor, as ciências físicas, naturais e outras teriam esquecido o conteúdo humano, a subjetividade originária do homem. Teriam se esquecido de ir ao encontro da origem do conhecimento, da gênese, da apreensão fenomenal da experiência vivida pelo sujeito: a percepção (Husserl, 1975). Para ele, este esquecimento se constituía em um ensaio para neutralizar a reflexão sobre as coisas e conceber o mundo como um campo estático às imposições do pensamento, ou seja, um mundo externalizado e desconectado das categorias lógicas de apreensão. Nesta construção científica, o sujeito era visto como um terreno vazio de representações, passivo no mundo, enquanto este era um objeto dado.

Ao tentar resolver as polêmicas sobre o binômio sujeito-objeto, ele negava a tese natural da existência, porque não concebia o mundo sem o sujeito. A consciência se revelaria na representação do mundo e, a partir daí, os objetos seriam alimentados pela intencionalidade da consciência. Neste entendimento, o mundo repleto de significados e mediado pela subjetividade seria marcado pela presença de um homem concreto a operar conhecimentos. Para o pensamento husserliano, objeto e sujeito se reúnem na mesma realidade, em cuja proposição nem a objetividade nem a subjetividade poderiam basear-se em uma suposta verdade, mas deveriam fundamentar-se na dinâmica de uma intersubjetividade que viria a apoiar um coletivo aberto e inesgotável, gerador de diferentes percepções emergentes em seus contextos situacionais, a ser partilhado e criticado.

A tese fenomenológica inaugurada por Husserl (1975) e mais tarde reinterpretada por outros autores, trata de dar significados à reflexão, tomando por base a redução do objeto a ser investigado, para estudá-lo de modo mais profundo - como um foco de luz a iluminar algo a ser apreendido e libertá-lo ao mundo. 
No dizer de Heidegger, esta tese refere-se a algo que se mostra desfigurado ou velado, o qual a fenomenologia deve "fazer ver" (Heidegger, 1997), ou ao sentido de algo que, não ausente, pode encontrar-se silenciado, interdito, velado, e tornar-se fenômeno quando desvelado. Em outros termos, para este autor, fenômeno não é tão somente a manifestação da consciência e da subjetividade transcendental como diz Husserl, mas, uma revelação do ser, pois este se apresenta como é e como se manifesta. Neste aspecto, Heidegger considera que o desvelamento do ser fundamenta a compreensão da existência (essência) humana, pois não há, para ele, uma separação entre compreensão, ser e mundo. E o ser, ao revelar-se na linguagem, expressa a compreensão e o pensamento do homem. Assim, a problemática interpretativa se impõe à dimensão ontológica e a ontologia descobre a sua base hermenêutica, a qual resgata da história do ser a sua visão ôntica (Heidegger, 1991). Deste modo, entende-se que a ontologia é fenomenologia e esta é hermenêutica. Com esta premissa, a contribuição de Heidegger imprime uma reflexão mais ampla da teoria da hermenêutica, em comparação com seus antecessores (em especial, Husserl e Dilthey).

A superação da metafísica mostrará que o ser sempre se vela no ente, e que o homem tende a esquecer este velamento. Segundo Heidegger (1997), "a ciência não pensa". Em outras palavras, o sentido é o tema central para o ser no tempo e o termo "fenômeno" diz mais que uma "mera manifestação", este autor ainda acrescenta: "o que faz ver, assim como". Nessa expressão, o parecer e a aparência se inter-relacionam para significar mais do que se quer mostrar e refere-se a "mostrar-se em seu sentido", pois nem tudo que parece se revela em seu sentido real (Heidegger, 1997).

O interrogar sobre o ser-no-mundo, em sua cotidianidade, encontra nesta concepção ontológica da existência dois fundamentos: o ser que se relaciona com as coisas do mundo objetivo, quer dizer, os objetos, e com as realidades exteriores as quais por si mesmas não são objetos. Neste último o "eu-coexiste", e a existência se realiza ôntica e concretamente no nosso ser em comum. Trata-se do ôntico para a compreensão do sentido que se mostra, o qual, no estudo etnográfico referente ao fenômeno da fome, quer dizer o sentido da fome que se mostra. O ser com fome manifesta-se no "eu faminto", e procura com um "outro faminto" compreender a fome que os cercam.

Também Paul Ricoeur traz contribuições importantes para o método da interpretação, ampliando a possibilidade de leituras sobre um dado fenômeno. Em sua teoria sobre a hermenêutica, ele busca fundamentar a dialética entre o evento lingüístico e o significado, o sentido e a referência, estabelecendo para o discurso escrito a relação do autor e do leitor do texto, em uma autonomia semântica a tornar ainda mais complexa a interpretação de um fenômeno. Neste aspecto, diferentemente de Dilthey e Heidegger, a ação como um texto tem um sentido independente da intencionalidade do ator, ou, ainda, um significado encontrado no contexto sócio-histórico da ação. No ato interpretativo, há uma dinâmica sempre renovadora, ou seja, um movimento que transcende à perspectiva do diálogo e à intencionalidade do ator em relação ao seu discurso (Ricoeur, 1990).

Esta breve revisão de algumas abordagens metodológicas não pretende confrontar de modo profundo os filósofos aqui mencionados, mas levantar elementos importantes para o processo da interpretação, sobretudo, a hermenêutica descrita por Paul Ricoeur e a utilização deste instrumento para a significação do fenômeno estudado. Assim, entende-se a fenomenologia aplicada neste trabalho como uma correspondência aberta, na qual se torna possível o exercício da hermenêutica para o desvelamento das experiências do homem, em um processo que sustenta estruturas do conhecimento em crescente aprimoramento e incitadas para a reflexão (Costa, 1985). E toda a cognição será inserida no espaço pré-teórico do mundo da vida; este lugar não 
teórico, cercado pela incógnita do não pensado e anterior à experiência teórica, é a presença de uma região onde o homem situa e tece uma infinita teia simbólica e reflexiva da realidade.

A subjetividade intrínseca à experiência descobre horizontes, e estes, progressivamente, revelam a realidade a ser partilhada. 0 conhecimento partilhado, o saber prévio, o consenso, etc., são expressos, precedendo e garantindo a relação entre os indivíduos. E da interação entre os sujeitos nascem as possibilidades da construção conjunta do sentido em decorrência de uma certa relativização de um mesmo sujeito e de outro. Neste processo interativo, supostamente, torna-se incerta a natureza de um eu solitário na produção de um enunciado (Tasca, 1985). Deste modo, para o faminto, o sentido da fome não é uma construção solitária, pois ele compartilha o fenômeno com seus pares.

Para a fenomenologia, o homem é lançado ao mundo, no qual sempre esteve presente, em uma situação não escolhida por ele, e passa a atribuir sentido à sua existência organizando os objetos do mundo à sua volta. Nesta aventura, ele transcende à atitude naturalista, quando explora o mundo da vida para dar uma descrição direta da experiência como ela é, sem levar em conta as explicações causais, mas considerando as coisas que fazem sentido para ele (MerleauPonty, 1996).

Sobre tais aspectos, Schutz (1979), ao traçar fundamentos para a fenomenologia, incorpora alguns conceitos básicos para a compreensão da vida cotidiana, vinculando a visão fenomenológica de Husserl à Sociologia Compreensiva de Max Weber. A partir de seus estudos, ampliam-se as características da compreensão, do significado subjetivo e da ação. O ponto principal é o mundo cotidiano, do sentido comum, e este é o campo da ação social que inscreve a subjetividade e gera a possibilidade de compreender a ação do outro, ou seja, a intersubjetividade (Panizza, 1981).
Ao abordar a perspectiva fenomenológica, escolhe-se, portanto, um movimento o qual permite uma maior aproximação de um dado objeto. Entende-se que este método qualitativo possibilita a observação e a descrição de como ocorre a experiência através da qual se conhece o objeto investigado, reavivando a temática suscitada e permitindo a compreensão dos diversos significados oferecidos no interior das relações cotidianas.

\section{A compreensão da fome no cotidiano}

A etnografia da fome, toma como pressuposto que ela é um fenômeno produzido pelo contexto político, social, histórico e econômico de nossa sociedade. Entretanto, estes elementos do tecido macrossocial estão inseridos no mundo íntimo e cotidiano, conforme a interpretação dos famintos. Melhor dito, a fome é caracterizada como um fenômeno a ocupar um lugar na dimensão sociocultural do mesmo corpo biológico que a sente, pois, pelo testemunho dos atores, os seus sentidos recorrem a uma complexa associação entre os efeitos do espírito sobre o corpo e vice-versa. Conseqüentemente, tanto os sentimentos como os aspectos orgânicos transcendem à semiologia descrita na literatura científica. Para eles, sentir fome não quer dizer apenas a sensação de vazio do estômago, mas significa, antes, a fraqueza do espírito. Também, observa-se que a fome não está ancorada à dimensão clínico-patológica como o termo desnutrição sugere ou anuncia nos cenários das ciências da saúde. Sobre isso, uma faminta do bairro diz: "Eu sinto uma agonia no peito, só de pensar que essa coisa, essa criatura (a fome) pode chegar na minha casa (no corpo)". [...] "Ela (a fome) ataca a pessoa que é fraca [...] não tem esse negócio de ser magro ou gordo não, tudo depende da natureza da pessoa".

De fato, as representações da fome colhidas na etnografia estão condicionadas à tradição de como a comunidade apreende 
diferentes sensações. Este conhecimento apresenta uma série de significados os quais se encontram como enunciados culturais, cujo entendimento requer a compreensão de variados elementos para a explicação da sobrevivência no mundo, como as crenças, os hábitos e tantas outras capacidades adquiridas.

Observa-se, ainda, que o homem faminto e mundano interpreta e compreende sua fome, desvelando-a como uma figuração, uma qualidade ou um julgamento sem uma estrutura de fundo claramente definida. Em outras palavras, o fundamento para uma outra leitura sobre a experiência de fome não se reduz ao conglomerado de sensações físicas, mas àquelas vividas pelo indivíduo e por outros, em uma intersubjetividade de apreensão do mundo, em meio às ambigüidades, em um nível da pré-reflexão.

Segundo esta prerrogativa, a sensação de fome de um pode ser distinta daquela de um outro também faminto, mesmo havendo "algo" comum entre eles, porque as coisas do mundo não se impõem ao homem de uma forma linear ou causal. Também, o que é percebido em um momento pode ser alterado e percebido de outra maneira, em um momento seguinte (Merleau-Ponty, 1996). A abordagem fenomenológica vem revelar os significados da fome a transcender à imagem corpórea da carência de alimentos, indo ao encontro de outras concepções sustentadas por um sistema de símbolos e geradas pela insegurança concreta de alimentar-se.

A experiência do faminto se constitui como vivências no nível da consciência e encerra significados que objetiva e subjetivamente são atribuídos pelo sujeito ao tentar compreender sua condição de faminto. No sentido comum do mundo da vida cotidiana, o ser com fome entende os motivos que o levam a agir sobre ela e a construir seus significados. Ele interpreta, na vida diária, o seu próprio mundo e explica o processo de fome, compreendendo-o em sua própria situação biográfica, e, assim, passando a considerar natural o modo como vive (Schutz,
1979). A compreensão deste seu universo, associada a esta premissa, sedimenta experiências adquiridas para formar a "bagagem de conhecimentos disponíveis", que funciona como um esquema de referência para toda a interpretação das coisas do mundo (Capalbo, 1979).

Assim, pode-se entender um modo pragmático de atenção à sobrevivência, o qual, por sua vez, está condicionado às "esferas delimitadas de sentido". Os sentidos e as sensações percebidas são delimitados por estilos cognitivos particulares, neles intervindo diversas características relativas à tensão específica da consciência, retratando a forma de espontaneidade e de determinada experiência (de alimentar-se, sentir fome, etc.), que depende da sua sociabilidade e da perspectiva temporal (Schutz, 1979).

Para Schutz \& Luckmann (1973), as fronteiras dos sentidos do homem no mundo da vida cotidiana são tomadas como real ou quase, para conferir o caráter de realidade ou quase-realidade a um fenômeno.

Neste aspecto, para os moradores do bairro onde foi realizada a etnografia, a condição de fome nem sempre é percebida por eles como uma produção da pobreza, mas, antes, é vista como um fatalismo que habita o seu mundo. Com isso, o faminto analisa este fenômeno como um fantasma a rondar sua casa e seu corpo. Trata-se de um objeto externo ao corpo, cuja externalidade ele persegue. Através desta conotação, presente em seu discurso habitual, ele transforma a sensação de fome do corpo em outro sentido o qual transcende a esta matéria física. Ou seja, no discurso do faminto emerge um texto cujas idéias nem sempre são definidas pela realidade, mas são manifestadas pelas interpretações.

É na linguagem que o homem procura articular-se com os vários aspectos do mundo, em um todo significativo para ambos e externalizar o sentido consentido para expressar, na intersubjetividade, as experiências do seu cotidiano. Desta forma, homem e mundo, em uma 
condição subjetiva/objetiva, deixam transparecer semelhanças e diversidades entre os seres humanos, na mesma realidade.

Por esta razão, atribui-se valor aos significados subjetivos expressos nas palavras dos atores sociais, tomadas no processo da observação. Esta condição pressupõe um nós, em termos de entrar no mundo dos significados sociais, que, de alguma maneira, podem ser compartilhados (investigador e investigados), respeitando as especificidades dos famintos e dando-lhes visibilidade, através do livre curso dos seus discursos.

\section{A linguagem revela o mundo}

"O homem vive com seus objetos fundamentais e até exclusivamente, tal como a linguagem Ihos apresenta, pois nele o sentir e o agir dependem de suas representações [...] Cada linguagem traça um círculo mágico ao redor do povo a que pertence, círculo do qual não existe escapatória possivel" (Cassirer, 1972).

O familiarizado com o cotidiano se expressa por uma linguagem a qual reitera, através da utilização de signos constitutivos, a perspectiva do mundo ordinário (Faustino, 1995). A linguagem revela as coisas e lhes dá significados. Este é um processo complexo, como mostra Wittgenstein (1996), ao conceber em uma de suas teses que toda palavra tem um significado e este está correlacionado ao objeto substituído por ela. Ou melhor, o significado vem corresponder ao objeto em si. Para este autor, em suas Investigações Filosóficas, uma expressão torna-se significativa quando é compreendida na prática da linguagem, no uso comum das palavras, no modo de comunicação no mundo.

Na complexidade do processo lingüístico, observam-se qualidades reflexivas e pré-reflexivas que comandam o movimento do eu, o qual se externaliza ou se internaliza na linguagem. E, ao externar as vivências internas, nem sempre há palavras em suficiência para dar significação ao que se quer manifestar. Por exemplo, em um grito de dor, o sujeito não pensa primeiro para exteriorizá-la, nem elabora ou escolhe formas de expressá-la. Também, o sujeito, ao sentir angústia por fome, externaliza de alguma maneira ao outro este sentimento para que ele seja conhecido. No movimento irrefletido, as sensações vêm antes da aquisição da linguagem verbal e, como simulacros, as manifestações naturais e instintivas cumprem finalidades próprias de uma situação específica. O sujeito se abre para se inter-relacionar com o outro, pois a gramática da exteriorização é parte da linguagem a ser compreendida por outra pessoa (Faustino, 1995).

No estudo dos significados da fome, produz-se uma semiologia particular da sua sensação, na qual revela-se a dor no peito como um signo. Entretanto, a interpretação não associa esta dor a um possível processo patológico no tórax, mas, contrariamente, considera-a uma expressão dada pelo faminto para informar ao mundo um estado interno de angústia por fome, ultrapassando o idioma da fisiologia a qual relaciona a dor de fome àquela na região do estômago. Nesta percepção, o sujeito transcende à dimensão corporal e situa a fome no lugar da indicialidade do eu, pois é o eu que dói. A identidade de faminto corresponde a este tipo de sofrimento expresso, ou seja, ele não segue as regras da gramática da clínica, e externaliza ao outro o que concebe gramaticalmente em seu mundo.

Para os atores sociais a fome é "uma criatura", ou "um demônio", ou "um vento", que anda pelo bairro, assusta, provoca dor e pode matar quem a percebe e sente. São estes, entre outros, os diversos sentidos e seus efeitos (metáforas), os quais, na dimensão simbólica, no mundo da linguagem e da cultura, expressam o fenômeno. As metáforas dos sentidos de fome têm muitas moradas no corpo: o peito que dói, a cabeça que endoidece, as pernas que não querem mais andar, etc. 
Com a linguagem, a historicidade imanente ao texto vem expressar-se na fala, a velar ou a desvelar os sentidos atribuídos pelo ator, para serem compreendidos pelo seu intérprete. Antes, uma pré-compreensão inspira o intérprete do faminto, antecipando um pré-texto, fundado no histórico da sociedade, para seguir em busca da compreensão fenomenológica de como o que tem fome textualiza sua experiência no contexto da vida cotidiana.

Para a fenomenologia, a observação direta e participante do mundo do ator e as suas falas são fundamentais para a compreensão do objeto de estudo. Por isso, recomenda-se aproximar-se do objeto, situando-o no mundo da vida cotidiana, e neste processo de aproximação a etnografia pode contribuir para deixar ver ou manifestar o que é possível apreender. E, quaisquer que sejam o objeto (o problema), o lugar e o sujeito, esta abordagem teórica permitirá a revelação de um conhecimento profundo, ocultado na relação, mesma, do sujeito/objeto da investigação.

\section{A tarefa hermenêutica para a interpretação do fenômeno da fome}

Para interpretar e compreender a realidade, a hermenêutica deriva do verbo grego hermeneia ou seja, a explanação que anuncia, à medida que se pode escutar uma mensagem. É a arte da interpretação, a qual na tradição grega está associada a Hermes, o Deus criador e mensageiro da linguagem entre os homens, tornando possível a compreensão humana. A hermenêutica, como teoria geral da compreensão interpretativa, transita em vários domínios: teológicos, lingüísticos, filosóficos, epistemológicos, etc. (Gadamer, 1997). Falar de hermenêutica é referir-se à linguagem, e a antropologia acolhe a hermenêutica da linguagem do homem sobre o homem (Cassirer, 1997); traz a dimensão social e cultural mostrada no próprio ato de interação entre o ator e o seu observador, tornando possível o sentido partilhado em sua pluralidade (Kristeva,
1974). Presença e diálogo formam, então, a intersubjetividade, na qual sujeito e objeto não se separam. Singularidade e pluralidade são dimensões correlativas, porque o eu carrega em si o que também está presente nos outros homens (Heidegger, 1997).

Na proposição acima, interpretar é conhecer a partir das palavras as quais fluem do diálogo, da linguagem, e compreender é tratar o homem como o sujeito que também quer compreender, à sua maneira, falando e interpretando as palavras escutadas (Ricoeur, 1987).

Conforme Ricoeur (1988a), do encontro mais amplo com a leitura relacionada ao contexto, promovem-se as "articulações entre o lingüístico e o não lingüístico da linguagem e da experiência vivida, no nível do texto". Para tanto, ele separa a leitura de um texto em duas fases recorrentes e complementares do processo hermenêutico: uma inicial, trazendo a objetividade textual, o que implica tentar compreender o texto conjeturando sobre o seu sentido, e outra seguinte, quando o texto se abre aos novos horizontes referenciais e o leitor elege o tratamento. Surge a explicação ou a explicitação da estrutura interna do texto, sem a preocupação com o sentido. Posteriormente, completa-se o trabalho hermenêutico, direcionando-se o sentido possível de cada situação do cotidiano.

Segundo a leitura de Casal (1996), a maior contribuição de Paul Ricoeur, ao método hermenêutico, está na analogia entre textos e ações sociais, o que garante um grau de objetividade e pertinência. Os textos e as ações, separados do ator (autor), podem ser interpretados independentemente do sentido subjetivo dado. $\mathrm{O}$ intérprete os situa nos diferentes horizontes, interligando o sentido que a ação significou ou significa para o ator e o sentido atribuído por ele, o intérprete. Trata-se de compreender a ação nos mesmos termos nos quais o ator social a compreende e a executa, sem estar dentro dele (Casal, 1996). 
O método hermenêutico proposto por Ricoeur possui os seguintes eixos juntos na linguagem (Ricoeur, 1997): primeiro, o diálogo, em um movimento dinâmico, transmite mensagens; depois, na passagem da fala à escrita, o discurso vira texto, em um movimento autônomo em relação à intenção do ator. O significado vai revelar-se no mundo do texto, o qual traz à tona a pluralidade do contexto onde foi produzido. Trata-se da libertação das palavras do ator, no ato da recepção de quem acolhe a leitura. 0 informante entra com as palavras e o leitor, com a significação.

"Essa autonomia do texto tem uma primeira conseqüência hermenêutica importante: o distanciamento [...] que é o constitutivo do fenômeno do texto como escrita; ao mesmo tempo, é a condição da interpretação" [...] e esta "passagem da fala à escrita afeta o discurso de vários modos, de uma maneira especial, o funcionamento da referência fica alterado quando não nos é mais possivel mostrar a coisa de que falamos como pertencendo à situação comum entre os interlocutores do diálogo" (Ricoeur, 1990).

No mundo do texto, então, será abolido o caráter de mostrar apenas a referência no discurso, e com isso ele se libertará para o mundo; esta visão também é compartilhada por Husserl e Heidegger. Esta abertura é considerada por Ricoeur fundamental para a interpretação. Para ele, é necessário explicitar o ser-no-mundo (na situação, no contexto) manifesto pelo texto do ator e interpretar sua proposição de mundo, para aproximar-se do cerne da questão, tornando o não familiar familiarizado, para sentir o texto. A leitura torna-se, ao mesmo tempo, irresistível e insustentável, em um permanente contraste (Ricoeur, 1987).

Para Ricoeur, o discurso apresenta dois pólos de tensão necessários à compreensão: o evento (alguém que fala) e a significação (a dialética da fala e da escrita). O que é compreendido é o sentido do discurso, a significação, a qual não se dá em um tempo linear entre a palavra e a frase, ou entre estas e a seqüência de um relato escrito. Nesta complexidade, comportam-se aberturas e tendências entre as temporalidades. Ou melhor, há um acordo entre as situações, existe um desfazer e uma reorganização provocados pelo distanciamento necessário à compreensão. A fala continua no texto, embora o locutor não esteja presente. O importante é o significado do texto, ou seja, a expressão de sua autonomia. No entanto, o autor (no caso, o faminto com sua fala) emerge inevitavelmente e traz ao leitor a complexidade da interpretação (Ricoeur, 1987).

A dupla dimensão da significação oferecida pela subjetividade e pela objetividade traz a polissemia e a ambigüidade das narrativas, as quais são filtradas pela função contextual, reduzindo a diversidade das interpretações possíveis. Assim, o informante tem em si a autocompreensão de sua condição no mundo, e será sempre um protagonista a interpretar a história social. Acompanhando este raciocínio, a referência de fome abre-se e segue-se a compreensão do texto do faminto, com o confronto de todas as significações possíveis no contexto social.

A despeito disso, entende-se que a linguagem não limita a compreensão e a interpretação ultrapassa os limites da fala para reafirmar um diálogo no qual a teoria (saberes) e a prática (a experiência vivida) são inseparáveis para o entendimento do fenômeno da fome. Para tanto, apreende-se um sistema significante para a leitura e, sobretudo, alguns momentos semiológicos para ampliar a noção de texto e, finalmente, significar o tema (Barthes, 1997). Ainda segundo este autor, a partir dos postulados de Saussure a semiologia tem como objeto o sistema de signos, e seja qual for sua substância e seus limites, as imagens, os gestos, os sons, etc. de qualquer espetáculo constituem-se como sistemas de significação. São os signos para além da linguagem. Apesar de trabalhar com substâncias não lingüísticas, o semiólogo é levado a encontrar, na linguagem, uma mediação para 
o significado de seu objeto. Trata-se do que ele chamou de segunda linguagem. Não serão fonemas ou monemas, mas fragmentos do discurso, a significar sob a linguagem e nunca sem ela. Nesta premissa, os mitos, a narrativa, os artigos de imprensa, os objetos são também falas.

Teoricamente, a conduta humana, independente da interação social - nas análises de Geertz (1989) e Ricoeur (além de outros autores, principalmente os adeptos da antropologia interpretativa) - pode ser representada em forma de texto. A história, a cultura, a sociedade são, portanto, "textualizáveis". Mas é, em especial, Ricoeur (1988b) quem inscreve o significado de um fenômeno e a condição situacional do agente. Este age e se movimenta em torno do que acontece.

Em suma, a hermenêutica ricoeuriana se apóia em instâncias que transcendem ao diálogo. Com isso, relacionam-se os sentidos expressados e outros conteúdos, sinalizando os componentes de mediação dos significados, em um exercício que contempla narrativas e signos. O trabalho do intérprete não se reduz a reescrever e a reconstruir o texto de um discurso, mas consiste também em interrogar-se, extrapolando-o. Estende-se ainda, concebendo sempre a possibilidade de conexões reais entre texto e contexto, tornando "a análise mais sutil e interdisciplinar" (Ricoeur, 1987). E os múltiplos sentidos observados podem ser tratados em dois níveis: o da palavra, e o do contexto que define o sentido expresso na palavra. A multiplicidade de sentido pode se dar no texto e não no nível da palavra, porque esta não consegue dizer tudo. Além disso os muitos sentidos podem ser contraditórios, em um nível propriamente hermenêutico, em uma diversidade interpretativa própria da vida (Franco, 1995).

Assim, dada a dificuldade que os informantes do bairro têm em expressar lingüisticamente o termo fome, os aspectos não lingüísticos enriquecem seus textos e constroem uma via necessária à compreensão do fenômeno. Por exemplo, a fome, quando expressada como uma "coisa", mostra-se quase sempre acompanhada de gestos de pavor. A coisa produz sensações de "arrepiar quando a gente sente que ela [a fome] vai chegar [...], vai arrancar as carnes do corpo". Estas e outras percepções dos sentidos transitam sem cessar por entre as vias concretas de um cotidiano o qual se quer compreender.

A condição intersensorial, referida como uma unidade da coisa por Merleau-Ponty (1996), pode ser aqui aludida como um resultado polissêmico, para situar o sentido último desta unidade mundana e real chamada fome, percebida em uma diversidade de significantes, apoiados em sentidos que se mesclam fenomenologicamente.

Os significantes são os objetos-signos de uma semiologia do corpo faminto, a contar com os vários signos relacionados à lingüística. Nesta perspectiva, a narrativa, outras expressões e objetos vão constituir os significantes a comporem o texto dos famintos.

Nesta concepção, a imanência do discurso e a transcendência articulam os sentidos e expressam os seus significados. Através desta conexão de sentidos e referências, os agentes assumem suas visões em meio às suas condições sociais concretas. Segundo uma faminta: "Eu estou nessa porque não tenho trabalho nem uma aposentadoria. Não é moleza ficar aqui esperando a bicha sem saber o que fazer pra me afastar dela". Suas palavras e suas frases, associadas aos muitos signos, constituem textos abertos ao mundo. Textos de uma autonomia semântica, porque vão além do acontecimento da fala, e seguem em direção ao significado possível. Uma inscrição dada pela intencionalidade do ator, em uma autonomia a ultrapassar a finitude do seu horizonte, significando mais do que ele quer dizer. São os textos da experiência de fome, reveladores de situações.

O texto é o questionamento do sujeito no seu mundo habitual. Plural e polifônico, ele presentifica o trabalho da significância, tomada no ponto atual da história. Ou seja, ele é aquilo que se deixa ler através da particularidade da 
conjunção de diferentes estratos da significância, presentes na língua e memorizados pela história. Com uma múltipla dimensão interativa, o texto é plural em significantes, os quais se interligam de modo continuum, inseparáveis do contexto social. A intertextualização manifesta a combinação das observações do real e do ideal imaginado, da materialidade e da abstração, oferecendo interpretações aproximadas e também amplas da realidade (Kristeva, 1974).

Segundo Ricoeur citado por Bakhtin (1979), no texto do falante, a significância vai além da fala, ou torna-se translingüística, pois o dialogismo da linguagem compreende as relações intertextuais. A palavra é significada dentro de um contexto social, em um processo narrativo que ultrapassa as relações significante-significado, em um diálogo que transfere a condição de sujeito da narração ao destinatário. Este, o sujeito da leitura, é o intérprete daquele que enuncia algo para si mesmo e para o outro.

Com esta mediação, o faminto frente ao espelho situa o espaço da representação para si e para o outro, em um movimento dialógico, onde o interlocutor devolve ao sujeito-autor, o eu-para-o-outro (Bakhtin, 1979). A relação especular sustenta no diálogo as vozes (que são sempre sociais) e outras dimensões (gestos, signos diversos), conformando um enunciado de diferentes elementos (culturais, históricos sociais, lingüísticos), que interagem semioticamente (Zoppi-Fontana, 1997). Deste modo, as metáforas das vozes e dos olhares dos famintos somam-se para dar lugar aos espaços representacionais deste grupo social.

Assim, na proximidade do tema, no diálogo, percebe-se a metáfora inscrita por uma faminta quando ela olha em direção ao seu corpo ou às alturas ou ao chão, em busca de outras correspondências que traspassam os morros do bairro, e percorre o passado com sua história, as ruas da cidade, o lixo dos mercados, etc., ou quando ela entra em silêncio ampliando o texto para além da fala. Esta atitude lembra as palavras de Orlandi (1993) ao escrever:
"Chegamos então a uma hipótese que é extremamente incômoda para os que trabalham com a linguagem: o silêncio é fundante. Quer dizer, o silêncio é a matéria significante por excelência, um continuum significante. O real da significação é o silêncio. E como nosso objetivo de reflexão é o discurso, chegamos a uma outra afirmação que sucede a essa: o silêncio é o real do discurso" (Orlandi, 1993).

Ao falar da coisa (fome) fora de seu corpo, o faminto a elege como uma terceira pessoa (um signo), um ente, que habita em seu horizonte, e diz: "É uma criatura que anda solta por aqui (o informante fica em silêncio e coloca as mãos a cobrir a face)" [...] "Uma bicha com a boca cheia de dentes [...] Eu sinto quando ela chega, tá aqui, tô sentindo ela, a peste" [...] "Olha só como eu fico..."

O sujeito fala (com a fome) para si, em um aparente monólogo: "Ela tá aqui escutando a gente, eu sei (olha para baixo, e entra em silêncio)". Neste estranho diálogo, ele evoca a entrada do silêncio, no qual se apoia para seguir abordando o assunto que parece temer. Para interpretar a aparente ausência do entrevistador, naquele momento, vale recordar que "o texto é um universo aberto em que o intérprete pode descobrir infinitas conexões" (Eco, 1997). Os espaços preenchidos constituem uma iniciativa de nossa interpretação, embora limitada. Esta ação é, de certo modo, instruída pela observação do contexto no qual se dá a fala (Eco, 1991).

As misturas de reflexões e sentimentos pessoais trazem uma encenação que considera a imagem enunciada, organizada para dar uma compreensão aos sentidos de fome. Em outros termos, seguindo Bréal (1992), a interpretação das metáforas leva em conta a externalidade do sujeito em relação a si mesmo; esta exterioridade é produzida pela linguagem e permite o mascaramento da fome. Nesta ação da linguagem, os sentidos de fome retornam ao 
sujeito e sustentam os sintomas de um processo real em seus efeitos.

A inscrição dos sentidos no texto se configura como um tecido a conformar uma textura de expressões e estruturas gramaticais as quais asseguram o significado que se quer dar. Deste modo, o faminto interpreta sua fome e o contexto sem separação, e convida o leitor a ver sinais, que culturalmente dão originalidade ao texto. Por certo, o seu sentido fala e representa a ação, situa no tempo e no espaço o lugar da significância na cena da realidade social e referencia o contexto particular, atingindo zonas onde residem a essência do significado que o faminto quer mostrar.

Entretanto, o texto não se contenta em representar para significar o real: vai além, rumo à ficção, alterando e transformando a realidade, gerando em torno dela um espaço de multiplicidade a conjugar exterioridade e intencionalidade, em uma rede de diferenças a marcarem a intensidade de sentidos para cada sujeito e as mudanças socioculturais entre os atores (Barthes, 1997). Por exemplo, os atores sociais, quando se referem a uma situação específica de desnutrição infantil, dizem: "Ele (o demônio, que quer dizer fome) chegou aqui e tomou conta do menino" [...] "Ele está assim desse jeito (desnutrido) porque a mãe vive na droga e não cuida dele" [...] "Foi o pai dele que deixou a família e ela ficou doida, aí quem sofre mais é o menino" [...] "Aqui é assim, só vive quem agüenta as coisas".

Os fenômenos são explicados no próprio estilo de ver o mundo, e o que é significativo para um enunciador pode não ser para um outro, na mesma realidade social. Em cada situação particular, em um processo dialético e contínuo, cada agente sente a fome crônica de modo singular, com sua própria história de vida, e constrói significados específicos, engendrando um texto igualmente específico para a compreensão do fenômeno.

Não se trata, pois, do caráter universal atribuído por Husserl para uma percepção da fenomenologia, mas de uma perspectiva relativizada, como descreve Merleau-Ponty ao entender a percepção como um produto particular de uma observação. Sobre isso, escreve: "...em lugar de abandonar todo o meu olhar no mundo, me volto para este próprio olhar e me pergunto: o que vejo exatamente?" (Merleau-Ponty, 1996). Nesta atitude, o sujeito se volta para si mesmo e percebe-se faminto: uma ação que o centra de modo cognoscente na cena objetiva. A reflexão, em um primeiro momento, afirma-se em uma dimensão subjetiva, depois se reconhece uma oposição, um contraponto, para finalmente se determinar limitações sobre um tema em análise (Franco, 1995). As contradições e as diferentes interpretações advindas de crenças irão compor um bloco de significantes a serem tecidos, em seus respectivos sentidos, mesclando-se e associando-se para dar significados (Ricoeur, 1988b).

Destas considerações teóricas nasce a possibilidade de examinar as narrativas dos famintos de modo minudente, ponderando os aspectos subjetivos da linguagem, em uma postura atenta à multiplicidade de elementos em volta do fenômeno, mas privilegiando-o. Neste processo de intersignificar, sintetiza-se o heterogêneo da percepção da fome em correspondência com as diversas experiências temporais dos atores sociais, em meio ao cotidiano da carência alimentar e de outras faltas.

Neste aspecto, o fazer narrativo vem resignificar o mundo na sua dimensão temporal. Esta resignificação deriva de pré-significados resultantes da ação humana. O sentido tende a transformar-se em significação, e a dimensão semiótica passa a ter, pela significação, uma dimensão semântica.

\section{A palavra fome torna-se oculta e explícita}

A etnografia do bairro traz alguns indicativos gerais, descritivos das experiências dos 
atores, em seus específicos contextos. Em um primeiro momento, o termo fome aparece na fala de mulheres e homens de diferentes unidades domésticas. São pessoas que participaram de lutas políticas pela melhoria do bairro e anunciam a palavra fome nos quadros de um contexto social e político, de modo claro, permitindo uma compreensão objetiva deste fenômeno na sociedade e, em especial, no bairro onde habitam. Entretanto, ao tratar do tema em relação aos seus corpos e dos membros de suas famílias, o termo se apaga.

A palavra fome também aparece de forma explícita na fala dos jovens do bairro, principalmente os envolvidos no tráfico de drogas. Referem-na como um sentido de morte, e a associam às experiências vividas nas suas infâncias e à condição econômica.

Em seguida, observa-se que o termo não aparece nos discursos dos personagens. Como um tabu lingüístico, a fome manifesta-se então velada e passa a ser substituída por símbolos.

Condenados a significar, os enunciadores revelam os sentidos da fome com o recurso de metáforas e usam gestualidades em lugar da palavra. Não há uma negação da condição faminta, mas uma tentativa de distanciamento. O sentido próprio do termo é tomado como um caráter de entidade, mas, em momento algum, há uma ausência do ator no palco. Permanece o sujeito a dialogar com seus objetos e a sentir a fome conforme suas crenças.

Inevitavelmente inseridos na história dos famintos, os aspectos econômicos e culturais aparecem nas narrativas como significantes de fome. Nesta perspectiva, as falas não estão dissociadas da atmosfera contextual conotada e dimensionada para dar um mínimo de interpretação ao problema.

Em outros termos, os vários objetos que convivem no mesmo espaço social constituem-se em combinações culturais heterogêneas, as quais se adaptam e se reproduzem significando e resignificando o fenômeno. Em especial, as combinações das diferenças intensificam o exercício da hermenêutica para interpretar um texto (ainda que fragmentado e parcial), o qual é sustentado pelo seu sentido histórico. Neste aspecto, a busca de coerência ao redor de um contexto específico consiste em encontrar um acordo com o estranho, o adverso, para obter-se alguma correspondência (Gadamer, 1997).

Este processo funda a compreensão, em um agir cuja base é a antecipação do sentido histórico do fenômeno, sempre renovado em um contínuo circular em torno do problema. Este circuito nunca se esgota, porque a compreensão será sempre submetida ao estágio provisório, em um tempo mortal. Desta insuficiência, subjacente a toda compreensão, nasce a expectativa, a busca da relação com a verdade, intencionada pelo texto (Gadamer, 1997).

Da pluralidade textual - que repousa na mesma condição plural de outros objetos da existência nasce um fio para a compreensão, o qual conduz e é conduzido, agregando novos fatos, novas explicações fundadas em modos diversos de sentir as necessidades do corpo. Embora aparentemente o tempo e o lugar não exijam do sujeito substâncias para refletir sobre sua fome, o fato concreto o submete a regras cruéis no registro de uma realidade onde ele se apóia em variados tipos de significâncias para dar sentido à existência. E a palavra fome, quase sempre oculta na fala, está a um só tempo explícita nos muitos signos que informam sobre os sentidos da vida em condições de precariedade.

\section{Os instrumentos do ato interpretante}

Não obstante a narrativa acolhida, com as figurações da infância mescladas aos acontecimentos diversos do cotidiano, a interpretação e a reinterpretação seguem para além da contemplação sobre o tema. Como uma "província da compreensão", no dizer de Paul Ricoeur, o ato interpretante é povoado de idas e 
vindas ao texto, para explicar e esclarecer lacunas (Ricoeur, 1988b). Um ato tenso, que regula a ansiedade de respostas, as quais são infinitamente inesgotáveis para a compreensão. Mesmo havendo uma relação abismal entre os personagens envolvidos no processo da investigação, com distâncias sociais e culturais profundas, o pressuposto é de uma interseção do mundo do texto com o mundo do leitor, possibilitando a transposição dos abismos entre os mundos. No encontro humano real, ou quase real - e também conflitivo, porque é supostamente mediado por sentimentos - entre o informante e o pesquisador, busca-se interpretar aproximando os mundos para a compreensão do fenômeno.

Esta é uma das premissas para iniciar o processo interpretante: afastar-se do estranhamento da cultura e dos sistemas de valores dos informantes e entender a referência do sujeito, para manter uma correspondência entre texto e fala. Assim, a interpretação adquire uma semelhança, e o texto passa a assemelhar-se à fala. O que torna possível para o faminto interpretar sua própria fome como fenômeno é o fato de ela ter se tornado inevitavelmente familiar, ou seja, um habitante do seu mundo. O faminto se apóia neste lugar, com mais ou menos conflitos, porque conhece o previsível, o horizonte permeável entre o ambiente familiar e o exterior, onde se situam os modos e os medos de sentir fome. São sensações comuns no conjunto a compor o novelo de sua existência, as quais, mesmo sendo expressas com dificuldade ou relegadas ao plano do invisível e do indizível, não são por ele negadas.

Deste modo, fenomenologia e hermenêutica prosseguem em direção às respostas e interrogações, nas múltiplas maneiras de ver e sentir a questão, na ação interpretante. Ou seja, o fenômeno da fome é hermenêutico em sua essência.

Da objetividade textual, a qual implica tentar compreender conjeturando sentidos, à abertura aos novos horizontes referenciais, elege-se uma leitura viva, resultante de uma dinâmica que reorienta seres reais e fictícios, identificando e reidentificando os muitos sentidos expressados.

Nesta trajetória, aproximam-se os sentidos não só da realidade da vida dos famintos como também dos símbolos adotados por eles para representar sua existência. Os conhecimentos expressados e as histórias de vida passam a revelar elementos para a interpretação, reflexionados pela história social. Com isso, na experiência dos famintos, as influências sociais e culturais e a linguagem se constituem em uma infinitude no processo de interpretar para compreender a fome.

O textual das narrativas explicita, na interpretação, os tantos temas humanos interativos à fome. Assim avaliando-se as inúmeras mensagens expressadas, extrai-se o objeto de estudo através de configurações e associações, elegendo palavras e sentenças significantes em cada contexto observado (Quadro 1).

Os produtos se combinam entre si e circulam por entre as narrativas, condicionados pelas características pessoais dos atores, conduzindo às expressões mais significativas do estudo. Há indicialidades presentes no jogo da linguagem e nos diversos semas (o tom de pavor das vozes, os gestos e outras expressões indicadoras) transituacionais, que se correspondem com as distintas experiências dos sujeitos.

Em um primeiro momento, diversas expressões são interpretadas como unidades referenciais em correspondência com o corpo; depois, são conectadas aos sentidos de fome. Neste procedimento, as unidades significantes se mostram representadas em outros textos originários e o contexto orienta a compreensão dos significados da fome de cada enunciador.

No processo minucioso de leitura, conjeturando os signos observados, utiliza-se as muitas entradas do texto dos famintos, seguindo o agrupamento mecânico das narrativas, para formar os subconjuntos temáticos das unidades significantes e seus sentidos atribuídos. A seguir, são construídas as categorias como ramos centrais da imensa árvore dos enunciados, 
Quadro 1. Configurações e associações.

\begin{tabular}{|c|c|c|}
\hline Significantes & Polissemia & Significação \\
\hline Dor no peito & Sente rasgar, sente uma coisa & $\begin{array}{l}\text { Medo da fome quando o filho foi preso, quando está sem } \\
\text { trabalho. }\end{array}$ \\
\hline Vento ruim & A gente sente quando chega, dói o peito, dá insônia & $\begin{array}{l}\text { Quando tem polícia no bairro, tiroteio, aviso de morte, de doença, } \\
\text { falta alimentos, ficou desempregado }\end{array}$ \\
\hline Criatura do mal & $\begin{array}{l}\text { Dá arrepio no corpo, medo, pavor, dor no peito, agonia de noite, } \\
\text { insônia }\end{array}$ & A fome é um espírito de mulher \\
\hline Coisa & Dá arrepio no corpo, medo, vexame, preocupação & Aflição de fome \\
\hline Peste & Se chamar atrai coisa ruim, dor no peito, um vexame & Polícia, traficante perigoso, fome, violência \\
\hline Inferno & Castigo, provação, abandonado por Deus & A vida e o bairro \\
\hline
\end{tabular}

tecendo-se algumas das unidades referentes e distinguindo-se os significantes polissêmicos e os significados correspondentes.

Os significantes recortados sobre o solo das narrativas são destacados para observar os sentidos, a dimensão empírica nos diversos momentos da investigação, donde parecem ecoar as vozes e o tom das palavras, até alcançar uma certa seqüência de curtos fragmentos contíguos ou léxicos (as unidades de leitura), com as palavras e as frases. Semiologicamente, trata-se de articular "a voz tecida com o texto" (Barthes, 1997). Neste exercício, a seqüência de ordenamentos nas sucessivas frases oferecem à leitura outros significados exteriores, assegurando uma maior visão dos sentidos.

As unidades léxicas (palavras ou frases significantes) das sentenças analisadas correspondem a uma parte do volume das muitas apreensões para significar o fenômeno. Rastrear cada uma destas unidades e tomá-las como potências interrogativas em relação ao texto dos famintos é uma tarefa inicial para a compreensão mínima dos significados. A pluralidade destas unidades situa os pontos migrantes por entre dimensões culturais do mesmo gênero, constituindo-se em um tecido entrelaçado de caracteres e símbolos que se assemelham e, algumas vezes, se opõem a um só tempo. Por exemplo, o significante criatura do mal produz uma pluralidade de sentidos: "arrepio no corpo", "medo", "pavor de pensar", "dói o peito", e faz o sujeito sentir "agonia de noite" e "insônia", para significar a fome como "um espírito de mulher, que chega de noite". Com a diversidade textual, elege-se os subconjuntos de significantes (vistos acima), constitutivos de um sistema complexo de zonas temporais para cada contexto das unidades domésticas.

A partir das seqüências das falas dos famintos, o estudo tende a aprofundar a interpretação dos momentos de silêncios e pausas das entrevistas, revelando a constatação de referências que possibilitam a leitura sobre o medo da aparição da fome. Também, são diversos os elementos da condição social a se traduzirem como sentidos de fome aportados em crenças e símbolos para dar a compreensão da realidade.

Cada informante sente a realidade, experimenta a fome em seu corpo e a percebe em outros. São os significantes conotados das histórias de vida, articulados e associados à auto-referência e à heterorreferência, na implicação ou constatação de sentidos expressados em relação a si ou a uma alteridade (o outro semelhante, a divindade, a alegoria). Mas, fundamentalmente, vale reafirmar que o fenômeno em pauta não se encontra isolado, mas associado a outros, como a violência, o desemprego, etc., os quais também significam o mundo do faminto.

Trata-se, pois, de conceber e reafirmar a pluralidade da condição a cercar o faminto, entendendo que os sentidos têm moradas diversas encontradas fora da fala dos sujeitos e dentro dela, 
em um texto a se libertar do exterior ao interior do ser e vice-versa, seguindo o "movimento da compreensão que vai constantemente do todo à parte e, desta ao todo" (Gadamer, 1997).

Em síntese, o interpretar se detalha na leitura, observando-se os códigos e distinguindo-se os diferentes termos a dizerem sobre a fome. Destaca-se a importância dos diversos significantes entrelaçados e os sentidos oferecidos. Deste modo, desfiam-se as linhas e as entrelinhas das frases, na procura de diferenças e similitudes, em meio às ramificações das redes de relações entre os contextos, para tornar visíveis alguns dos significados compreendidos no estudo etnográfico.

\section{CONSIDERAÇÕ ES FINAIS}

O processo interpretativo indica que a fome é expressa independente das necessidades nutricionais do organismo, pois o idioma através do qual falam os sentidos de uma fome a ameaçar a vida traz os signos mais profundos do eu, no mundo habitual, não reduzindo este fenômeno às relações funcionais do organismo. A necessidade da produção de signos, por parte dos atores sociais, para interpretar sua fome, serve para identificar os sentidos e as emoções associadas, os quais dão lugar à compreensão de uma identidade faminta na condição social.

Ao organizar o passado no mundo da linguagem, o sujeito apreende sua condição de ser faminto, mas não rompe as amarras da fome impronunciável. Sua tendência é afirmar a incerteza de viver sem a presença da fome, sensação esta a persistir mesmo quando desaparece a carência imediata do alimento, tornando-a complexa em sua origem, e a perdurar sem repouso em todas as pessoas do bairro, apresentando-se com tipificações diversas, que orientam as interpretações manifestas.

Assim, a fome realça a fiação fundadora de uma realidade que se assemelha, onde os sujeitos se percebem semelhantes entre seus parceiros sociais, das mesmas ruas e becos do bairro. A fome povoa os horizontes de quem vive nestes contextos sociais e, por isso, pode ser sentida. Deste modo, conclui-se que as metáforas da fome apreendidas não são ilusões dos agentes, mas os efeitos dos sentidos. Desvelam-se significantes a se associarem a outros fenômenos e, através desta conexão, a fome pode manifestar-se como um ente do mal para significar a aflição crônica do desemprego, da falta de dinheiro para o leite da criança, além de diversos outros condicionantes sociais. Com isto, a produção sobrenatural de qualidade maligna funciona como um ponto de passagem da consciência para redefinir a existência faminta. $\mathrm{O}$ ente, a coisa, o vento ruim que chega para assombrar, etc., não são, pois, alegorias, ou estruturas soltas no vazio, mas formações interpretativas para validar, como conteúdos subjetivos, o objetivo de uma fome experimentada.

As evocações traduzem um mínimo de compreensão sobre a fome, produzindo a originalidade de significados. Esta produção se manifesta dentro do processo social e através dela se compõe o cenário de um mundo violento e faminto.

Para os moradores do bairro, o interesse não está em mostrar a fome de modo consciente. Por esta razão, os signos físicos não são os mais valorizados, e a estes se somam outros signos para explicar a sua real manifestação. Nestes termos, para suportar a sobrevivência, o faminto tende a afastar-se da fome em suas pré-reflexões e, em um tempo provisório de sua reflexão, ele não se limita a perceber os sentidos, mas também os utiliza em suas explicações recorrentes. Desta forma, ele nem sempre reflete a importância do peso corporal como um problema de saúde. Para ele tanto faz estar magro ou gordo, porquanto a fome está inevitavelmente presente no tempo da vida, como uma cicatriz da própria existência, independente do peso do corpo dos seus agentes. Neste aspecto, a concepção clínica de um estar nutrido significa para estes sujeitos estar faminto 
em suas realidades, pois o alimento em suas mesas será sempre provisório.

Os significados da fome engendram um texto específico para a compreensão do fenômeno, o qual é percebido como uma doença, mas, antes, revela-se como um estado da desvalorização social do sujeito perante o mundo, a sociedade. Uma desvalorização no sentido ôntico, pois ele não só se sente humilhado, como também se percebe sem qualquer esperança de sair das condições sociais em que vive.

As experiências de fome impõem, portanto, significados subjetivos para ordenar o mundo real. $E$, nesta construção da cultura, a condição de fome centra o sujeito em sua própria realidade. Para os famintos, "a vida não tem mais jeito", e só um "milagre" poderia reverter a desigualdade social que produz fome e transformar o bairro em um "lugar igual na cidade, sem essa coisa vim pra porta da gente".

\section{REFERÊ NCIAS B I B LIO G R Á F I C A S}

BAKHTIN, M. Marxismo e filosofia da linguagem. São Paulo: Hucitec, 1979. p.60-65, 360-369.

BARTHES, R. Elementos de semiologia. 10.ed. São Paulo : Cultrix, 1997. p.12-20, 25-46.

BRÉAL, M. Ensaio de semântica: ciência das significações. São Paulo : Pontes, 1992. p.157.

CAPALBO, C. Metodologia das Ciências Sociais: a fenomenologia de Alfred Schutz. Rio de Janeiro : Antares, 1979. Capítulo II, p.37-38.

CASAL, A. Para uma epistemologia do discurso e da prática antropológica. Lisboa : Edições Cosmos, 1996. p.49-66.

CASSIRER, E. La philosophie des formes symboliques. Paris : Minuit, 1972. p.36.

CASSIRER, E. Ensaio sobre o homem: introdução a uma filosofia da cultura humana. São Paulo: Martins Fontes, 1997. p.181-183.

COSTA, C. A fenomenologia e o significado da ciência. Revista Brasileira de Filosofia, São Paulo, v.34, n.138, p.149-160, 1985.
ECO, U. A estrutura ausente. 7.ed. São Paulo : Perspectiva, 1991. p.35-37.

ECO, U. Interpretação e superinterpretação. São Paulo : Martins Fontes, 1997. p.45.

FAUSTINO, S. Wittgenstein: o eu e sua gramática. São Paulo : Ática, 1995. p.20-23, 61-70.

FRANCO, S. Hermenêutica e psicoanálise na obra de Paul Ricoeur. São Paulo : Loyola, 1995. p.46-49, 85-89.

GADAMER, H. Verdade e método. Petropólis : Vozes, 1997. p.19-25, 52-53, 436.

GEERTZ, C. A interpretação das culturas. Rio de Janeiro : Guanabara, 1989. p.225-277.

HEIDEGGER, M. Conferência e escritos filosóficos. São Paulo : Nova Cultural, 1991. p.15, 35-40. (Os pensadores).

HEIDEGGER, M. Ser e tempo. Rio de Janeiro : Vozes, 1997. v.1: p.45-208.

HUSSERL, E. A filosofia como ciência de rigor. Coimbra : Atlântica, 1975. p.5-30.

KRISTEVA, J. Introdução à semanálise. Lisboa : Debates Perspectiva, 1974. p.11-14, 72-78.

MARTINS, J., BICUDO, M.A. A pesquisa qualitativa em psicologia: fundamentos e recursos básicos. In: UM SEMINÁRIO avançado em fenomenologia. São Paulo : Educ, 1997. p.21.

MERLEAU-PONTY, M. Fenomenologia da percepção. São Paulo : Martins Fontes, 1996. p.5-7, 88, 304, 368.

ORLANDI, E.P. As formas do silêncio: no movimento dos sentidos. 2.ed. Campinas: Unicamp, 1993. p.31.

PANIZZA, L. O pensamento de Alfred Schutz: sociologia fenomenológica. Temas em Debate, v.31, n.122, p.128-141. 1981.

RICOEUR, P. Teoria da interpretação. Lisboa : Editora 70, 1987. p.43-48, 62-74, 146.

RICOEUR, P. O conflito das interpretações. Lisboa : Rés, 1988a. p.20-65.

RICOEUR, P. O discurso da acção. Lisboa : Editora 70, 1988b. p.29-31, 159-160. 
RICOEUR, P. Interpretações e ideologias. 4.ed. Rio de Janeiro : Francisco Alves, 1990. p.20-28, 46-57.

RICOEUR, P. Tempo e narrativa. Campinas: Papirus, 1997. v.3: p.52-61, 280-283.

SCHUTZ, A., LUCKMANN, T. Las estructuras del mundo de la vida. Buenos Aires: Amorrortu Editores, 1973. p.27-43.

SCHUTZ, A. Fenomenologia e relações sociais. Rio de Janeiro : Zahar, 1979. p.49-51.

TASCA, N. Da interação e da gênese do sentido. In: DA SEMIÓTICA. Actas do / Colóquio Luso Espanhol e do II Colóquio Luso-Brasileiro. Lisboa : Vega Universidade, 1985. p.443-451.

WITTGENSTEIN, L. Investigações filosóficas. São Paulo : Nova Cultura, 1996. p.9-15. (Os pensadores).

ZOPPI-FONTANA, M.G. O outro da personagem: enunciação, externalidade e discurso. In: BRAIT, B. (Org.). Bakhtin: dialogismo e construção do sentido. São Paulo : Unicamp, 1997. p.115-123.

Recebido para publicação em 30 de novembro de 2000 e aceito em 12 de junho de 2001. 